\title{
Sleep disorders in menopause: results from an Italian Multicentric Study
}

M. FABBRINI', I. ARICÒ2, F. TRAMONTI', R. CONDURSO'², L. CARNICELLI', A. DE ROSA ${ }^{1}$, C. DI PERRI' ${ }^{2}$ E. BONANNI', M.R. BONSIGNORE ${ }^{3}$, A. ZITO ${ }^{3}$, G. RUSSO ${ }^{4}$, M.G. PAGLIARULO ${ }^{5}$, B. GUARNIERI ${ }^{6}$, G. CERRONI $^{6}$, G. MENNUNI $^{7}$, G. DELLA MARCA ${ }^{7}$, E. BONANNI', ROSALIA SILVESTRI ${ }^{2}$

\begin{abstract}
' Sleep Center, Department of Neurosciences, University of Pisa, Italy; ${ }^{2}$ Sleep Medicine Centre, UOSD of Neurophysiopathology and Movement Disorders, University of Messina, Messina, Italy; ${ }^{3}$ Department of Medicine, Pneumology, Physiology and Human Nutrition (DIMPEFINU), University of Palermo, Italy; ${ }^{4}$ Scientific Institute of Telese, S. Maugeri Foundation IRCCS, Telese Terme, Benevento, Italy; ${ }^{5}$ Laboratorio Neuropsicologia, S. Maugeri Foundation IRCCS Telese Terme, Benevento, Italy;

${ }^{6}$ Center of Sleep Medicine, Villa Serena Hospital, Sleep Center, Città S. Angelo, Pescara, Italy; ${ }^{7}$ Institute of Neurology, Department of Neurosciences, Catholic University, Rome, Italy
\end{abstract}

\section{A B S T R A C T}

Menopause in the female life cycle is a special period due to important hormonal, physical and psychological changes. Sleep disruption represents a common complaint for midlife and menopausal women, related to primary sleep disorders, including insomnia, sleep disordered breathing, restless legs syndrome (RLS), mood and anxiety disorder, other medical illness, hormonal-related vasomotor symptoms, and aging per se. Aims of our study were to evaluate the prevalence of sleep disorders in a sample of pre and post menopausal women, and to investigate the relationship between sleep and other medical disorders, and life habits. Among workers in the six participant centers, we enrolled 334 women, aged between 40 and 60 years, that completed a questionnaire that included screening on menarche, menstrual cycle, fertility, parity, menopause, life habits, personal medical and sleep history and related treatment, and self-administered scales for sleep quality (PSQI), excessive daytime sleepiness [Epworth Sleepiness Scale (ESS)], mood disorder [Beck Depression Inventory (BDI)], Berlin Questionnaire for sleep disordered breathing (SDB), IRLS diagnostic interview and Rating Scale. Menopausal and perimenopausal women showed an increased prevalence of poor sleep, high risk of SDB, and mood disorder; menopausal women also reported increased RLS severity. Mood disorder had a significant impact on night sleep measures and excessive daytime sleepiness, as well as on RLS severity, and had a greater prevalence in hypertensive women. Sleep disturbances are frequent in menopausal women. Their aetiology is unclear, but probably multifactorial, and many factors contribute to the sleep disruption. Our data suggest the importance of correctly investigating and addressing sleep problems associated with menopause, through sleep history, possibly carring out a sleep study if clinically warranted. Pharmacological and behavioural treatment strategies should then be aimed at improving sleep and life quality in perimenopausal and menopausal women.

Key words

Menopause $\bullet$ Perimenopause $\bullet$ Sleep disorders $\bullet$ Mood disorders

\section{Introduction}

Menopause is a life period during which women undergo significant physical and psychological changes. The beginning of menopause coincides with the start of symptoms related to hypertension, weight gain, hormonal modifications, osteoporosis and vascular disease. Hormonal changes could be 
responsible for certain sleep disorders, which play an important role during menopause. The prevalence of sleep disturbances is higher after menopause in women than before, independent of the effects of aging or other confounders (Xu et al., 2014). Women's sleep exacerbates with age both in quality and in quantity and during the peri and post-menopausal period, women very often experience insomnia, sleep disordered breathing (SDB) and restless legs syndrome (RLS) (Bruyneel, 2015). Insomnia is the most frequent sleep disorder in menopause. Primary or secondary insomnia can be due to vasomotor symptoms (hot flashes), mood disorders including depression and/or anxiety, and physical problems (bladder problems, low back pain, osteoarthritis, etc) (Culpepper, 2006). The SWAN study (Kravitz et al., 2003) found a significant association (OR 1,99, IC 95\%) between sleep onset insomnia and hot flashes in a multicenter group study of 12603 women aged between 40 and 55. Insomnia was present in $46-48 \%$ of menopausal versus $38 \%$ of premenopausal women.

SDB prevails in postmenopausal compared with to premenopausal women. Sleep apneas are predominant in males (M:F=8:1) with 3-4 fold increased SDB risk compared to premenopausal females. However, menopause increases the risk of developing Obstructive Sleep Apnea Syndrome (OSAS) (Guidozzi, 2013). In fact, menopausal women have a 2.6 to 3.5 fold greater chance of developing the syndrome compared to premenopausal women (Young et al., 1993). The changes in body fat distribution, including increased abdominal fat, the increment in waist to hips ratio, and weight gain due to higher levels of testosterone could explain the increased prevalence of SDB. Increased circulating testosterone may also cause the volumetric augmentation of tongue muscles with consequential obstruction of upper respiratory airways at the base of the tongue. Moreover, the fall of progesterone, with loss of its protective role, could be relevant to SDB. However, the existing literature does not agree on a positive univocal role for estrogen and progesterone therapy in controlling post-menopausal SDB (Guidozzi, 2013). SDB contributes to worsen sleep quality and quantity with appearance of daytime symptoms (sleepiness) and is known to play a role in the development of cardio and cerebrovascular diseases (Marin et al., 2005). Polesel et al. (2015) showed that
SDB abounds in postmenopausal women, especially in late postmenopause, and this increased prevalence is linked to waist circumference. Reducing waist circumference may thus constitute an important strategy for managing SDB in women.

In a recent study (Taavoni et al., 2015) sleep quality, measured via the Pittsburgh Sleep Quality Index (PSQI), was impaired in $70 \%$ of the sample. Another important study regarding menopausal women (Hachul et al., 2015) reported that premenopausal and post-menopausal women differ for apnea/hypopnea index (AHI) and for N3 sleep duration. Menopausal women had higher AHI and spent more time in N3 sleep compared to non-menopausal females. No differences were found between early and late menopausal women.

RLS is twofold more frequent in women than in men. Pregnancy and parity increase the risk of RLS. Some evidence suggests that dysfunction in iron metabolism and high estrogen levels might contribute to RLS during pregnancy. However, menopause is also related to an increased prevalence of RLS. Hormone replacement therapy (HRT) does not worsen RLS suggesting that the pathophysiology of this sleep disorder is not strictly linked to female hormones. Menopausal women who had previously experienced RLS symptoms often describe an exacerbation in the severity of the symptoms after menopause. (Manconi et al., 2012).

\section{Objectives}

Our study aimed to evaluate the prevalence of sleep disorders in a sample of pre and post-menopausal women, and to investigate the relationship between sleep, life habits and comorbidities in this population.

\section{Methods}

\section{Population}

Our sample was composed of women aged between 40 and 60 years, recruited from six participating Centers: 1. Sleep Disorders Center, Department of Neurosciences, University of Pisa; 2. Department of Medicine, Pneumology, Physiology and Human Nutrition (DIMPEFINU), University of Palermo; 3. S. Maugeri Foundation, IRCCS Telese Terme, Benevento; 
4. Casa di Cura Villa Serena, Città S. Angelo, Perugia; 5. Department of Neurosciences, Catholic University, Rome; 6. Sleep Center of Messina, in the role of the coordinating center, Physicians, staff nurses and administrative staff were included in the cohort. The respective local Ethical Committees granted their approval of this study. All subjects signed a written informed consent form and all the data were anonymously sent to the collecting center.

\section{Data collected}

We employed self-administered written questionnaires to obtain the following data: menarche, menstrual cycles, fertility, parity, menopause [defined as the permanent cessation of menses for at least 12 months, according to McKinkay et al. (2008)], life habits, personal medical and sleep history with related treatment, including neurological (headache, epilepsy), cardiovascular, metabolic and thyroid disease, and specific self-assessment questionnaires:

- Pittsburgh Sleep Quality Index (PSQI): an effective instrument that assesses sleep patterns and quality in adults, through 19 self-administered questions, regarding the previous month, from which 7 component scores are calculated and summed into a global score. These areas regard subjective sleep quality, sleep latency, sleep duration, habitual sleep efficiency, sleep disturbances, use of sleeping medications, and daytime dysfunction. Higher scores represent worse sleep quality: component scores range from 0 to 3, and global scores range from 0 to 21. A global PSQI score greater than 5 indicates poor sleep quality (Buysse, Reynolds et al., 1989).

- Epworth Sleepiness Scale (ESS): a self-administered questionnaire designed to assess the global level of daytime sleepiness, through the likelihood of falling asleep during eight normal, low activity daily life situations. Subjects rate their likelihood of dozing off on a scale of 0-3, with 0 being "no chance of dozing" and 3 being "high chance of dozing". The total score ranges from 0 to 24, with higher scores corresponding to greater sleepiness. An ESS score greater than 10 indicates daytime sleepiness and 18 or more is high daytime sleepiness (Johns, 1991).

- Berlin Questionnaire includes eleven questions, clustered into three categories, assessing sleep apnea risk. First category comprises five ques- tions concerning snoring and witnessed apneas, and their frequency. Second category comprises four questions addressing daytime sleepiness, including a specific question on drowsy driving. Third category encompasses two questions concerning high blood pressure $(>140 / 90 \mathrm{mmHg}$ ) and BMI $(>30 \mathrm{~kg} / \mathrm{m} 2)$. Category 1 and 2 are considered positive if there are two or more positive answers to each category, whereas category 3 is considered positive in case of self-reported high blood pressure and/or a greater than $30 \mathrm{~kg} /$ $\mathrm{m}^{2}$ BMI. Two or more of the three categories identify subjects at "high risk" of OSA (OSAS+), whereas less than two categories suggest a "low risk". (Netzer et al., 1999).

- IRLS diagnostic interview and Rating Scale (if RLS positive). RLS is diagnosed based on four diagnostic criteria: (1) an urge to move legs due to discomfort, (2) temporary relief with movement, (3) worsening symptoms at rest, and (4) worsening symptoms at night. International RLS (IRLS) Rating Scale is a 10-item scale that assesses RLS symptom intensity, frequency, and consequences on a 5-point scale. Global score ranges from 0 (no RLS) to 40 (very severe RLS) (Walters et al., 2003).

- Beck Depression Inventory (BDI) is a 21 multiple-choice self-administered questionnaire that assesses cognitive, affective, somatic, and vegetative symptoms of depression. A 0 to 3 score is assigned to each answer and a higher global score indicates more severe depressive symptoms. Commonly accepted ranges are 0-14 (no depression), 15-30 (moderate depression), and higher than 30 (severe depression) (Beck, Steer \& Carbin, 1988).

Among all the enrolled women, 334 correctly completed and returned the questionnaire and were hence included in our final cohort.

\section{Statistical analysis}

Statistical comparisons considered menopausal (no menses in the last 12 months: 105 women), perimenopausal (irregular cycles in the last 3 months: 42 women) and non-menopausal status (regular cycles: 187 women) as factors. Furthermore, life habits, medical history, and sleep data were examined, and different sleep comorbidities or drug use (sugges- 


\begin{tabular}{|l|c|c|c|c|c|c|}
\hline \multicolumn{2}{|l|}{ Table la. - Non-menopausal, perimenopausal, menopausal women. } \\
\hline $\begin{array}{l}\text { Non-meno- } \\
\text { pausal } \\
\mathrm{N}=187\end{array}$ & $\begin{array}{c}\text { Perimeno- } \\
\text { pausal } \\
\mathrm{N}=42\end{array}$ & $\begin{array}{c}\text { Meno- } \\
\text { pausal } \\
\mathrm{N}=105\end{array}$ & $\begin{array}{c}\text { Non menopausal } \\
\text { vs Menopausal } \\
\text { (K-W test) }\end{array}$ & $\begin{array}{c}\text { Non menopausal } \\
\text { vs Perimenopausal } \\
\text { (K-W test) }\end{array}$ & $\begin{array}{c}\text { Menopausal vs } \\
\text { Perimenopausal } \\
\text { (K-W test) }\end{array}$ \\
\hline Age, years & $48.4 \pm 2,8$ & $51.6 \pm 3.1$ & $52.0 \pm 2,1$ & 0.000 & 0.000 & N.S. \\
\hline $\begin{array}{l}\text { Total sleep } \\
\text { time, hours }\end{array}$ & $6.3 \pm 1.1$ & $6.8 \pm 1.1$ & $6.1 \pm 1.2$ & N.S. & N.S. & N.S. \\
\hline PSQI & $6.1 \pm 2.8$ & $7.6 \pm 2.6$ & $6.2 \pm 2.5$ & N.S. & N.S. & N.S. \\
\hline ESS & $4.9 \pm 3.0$ & $9.4 \pm 3.5$ & $6.7 \pm 4.0$ & N.S. & N.S. & N.S. \\
\hline BDI & $9.4 \pm 6.8$ & $15.8 \pm 7.0$ & $11.5 \pm 6.0$ & N.S. & N.S. & N.S. \\
\hline IRLS & $13.4 \pm 5.2$ & $14.8 \pm 3.6$ & $16.8 \pm 5.8$ & N.S. & & \\
\hline $\begin{array}{l}\text { PSQI=Pittsburgh Sleep Quality Index; ESS=Epworth Sleepiness Scale; BDI=Beck Depression Inventory. KW=Kruskal-Wallis. Data } \\
\text { are presented as mean } \pm \text { Standard deviation. }\end{array}$ &
\end{tabular}

tive of specific medical disorders) were considered. Insomnia was defined as difficulty in falling asleep (longer than 30 minutes sleep onset) and/or maintaining sleep and/or less than six hours of total sleep time. Comparisons between two groups were conducted through the Mann-Whitney non parametric test, whereas comparisons between three groups (menopausal, peri-menopausal and non-menopausal women) were executed through the employment of the Kruskal-Wallis test. Frequencies were compared using Pearson's chi-square test. Binary logistic regression was applied to evaluate the association between menopausal status, demographic data, life and behavioral habits, and sleep, medical and psychiatric variables, considering the various comorbidities and lifestyle habits as dependent variables. Univariate regression was employed to evaluate the impact of lifestyle habits on sleep and mood, applying sleep scales and BDI as dependent variables.

Data were reported as mean \pm standard deviation or percentage and were evaluated using the IBM Statistical Package for the Social Sciences, ver 13 (SPSS Inc, USA), considering a 2 -sided $\mathrm{p}$ value $<0.05$ as statistically significant for comparisons. Correlations were computed according to Spearman's Q, considering a $\mathrm{p}$ value $<0.01$ as statistically significant.

\section{Results}

\section{Menopausal status}

Compared to non-menopausal women, perimenopausal and menopausal subjects were older, presenting higher ESS and BDI scores. A trend towards shorter sleep duration and higher PSQI scores also emerged, with higher iRLS (Table 1a).

Compared to non-menopausal women, perimenopausal and menopausal women did not show any statistically meaningful difference in the main comorbidities investigated, except for an increased prevalence of mood disorders and more severe RLS symptoms in affected menopausal women. However, a trend for increased arterial hypertension and OSAS+ was found in our population, as well as decreased headache prevalence (Table $1 b$ ).

\section{Sleep disorders}

Insomniac women reported worse PSQI $(\mathrm{p}<0.001)$ and BDI $(\mathrm{p}=0.01)$ scores. An increased prevalence of RLS ( $\mathrm{p}=0.01$; OR=2.99) and headache ( $\mathrm{p}=0.03$; $\mathrm{OR}=2.28$ ) was highlighted in this subgroup, with a trend towards increased prevalence of mood disorders (18.8 vs. $25.6 \%)$ and more frequent shift work ( 24.5 vs. $37.2 \%)$.

A poor sleep quality (as defined by $\mathrm{PSQI}>5$ ) was associated with worse ESS $(\mathrm{p}=0.001)$, BDI $(\mathrm{p}<0.001)$, and IRLS $(\mathrm{p}=0.01)$ scores, as well as with mood disorders $(\mathrm{p}=0.002 ; \mathrm{OR}=3.48), \mathrm{RLS}(\mathrm{p}=0.04$; $\mathrm{OR}=1.79)$, and nicturia $(\mathrm{p}=0.028 ; \mathrm{OR}=3.07)$. A trend towards increased OSAS+ prevalence (20.6 vs $28.2 \%)$ and more frequent shift work emerged (20.8 vs. $28.2 \%)$.

Excessive daytime sleepiness (EDS), as defined by ESS $>10$, was associated with worse BDI $(\mathrm{p}<0.001)$ scores, as well as with increased prevalence of mood disorder ( $\mathrm{p}=0.05$; OR=3.30), RLS ( $\mathrm{p}=0.006$; $\mathrm{OR}=3.39$ ), and hypertension ( $\mathrm{p}=0.004 ; \mathrm{OR}=3.74)$. A trend towards higher PSQI $(p=0.067)$ score 


\begin{tabular}{|l|c|c|c|}
\hline \multirow{2}{*}{ Table lb. - Distribution of evaluated symptoms among non-menopausal, perimenopausal and menopausal women. } \\
\hline & $\begin{array}{c}\text { Non menopausal } \\
\mathrm{N}=187\end{array}$ & $\begin{array}{c}\text { Perimenopausal } \\
\mathrm{N}=42\end{array}$ & $\begin{array}{c}\text { Menopausal } \\
\mathrm{N}=105\end{array}$ \\
\hline OSAS+ & $22.5 \%$ & $21.4 \%$ & $28.6 \%$ \\
\hline RLS & $21.9 \%$ & $16.7 \%$ & $20.2 \%$ \\
\hline Insomnia & $13.4 \%$ & $9.5 \%$ & $13.3 \%$ \\
\hline ESS $>10$ & $5.9 \%$ & $9.5 \%$ & $9.5 \%$ \\
\hline PSQI >5 & $44.0 \%$ & $53.8 \%$ & $55.3 \%$ \\
\hline BDI>15 & $12.8 \%$ & $16.7 \%$ & $21.9 \%$ \\
\hline Hypertension & $10.8 \%$ & $9.5 \%$ & $11.4 \%$ \\
\hline Thyroid disease & $10.9 \%$ & $9.6 \%$ & $11.1 \%$ \\
\hline Headache & $51.7 \%$ & $48.3 \%$ & $40.3 \%$ \\
\hline Epilepsia & $1.3 \%$ & $0.0 \%$ & $1.5 \%$ \\
\hline Diabetes & $0.5 \%$ & $0.0 \%$ & $1.9 \%$ \\
\hline Nicturia & $3.8 \%$ & $9.8 \%$ & $9.6 \%$ \\
\hline OSAS+=high risk of sleep apnea according to Berlin Questionnaire; RLS=Restless legs syndrome. Data are presented as \%. \\
\hline
\end{tabular}

and increased menopausal status (30.8 vs. $40.0 \%$ ) emerged.

An analysis of the sleep comorbidities associated with OSAS+ revealed higher BMI ( $\mathrm{p}=0.001)$, PSQI $(\mathrm{p}=0.01)$, and BDI $(\mathrm{p}=0.03)$ scores, and a trend towards increased mood disorder (14.4 vs. $22.2 \%$ ) prevalence. RLS patients displayed increased BMI $(p=0.03)$ and BDI $(p=0.04)$ scores, as well as an increased prevalence of insomnia $(\mathrm{p}=0.001$; $\mathrm{OR}=2.99)$ and hypertension ( $\mathrm{p}=0.04 ; \mathrm{OR}=2.10)$; an increased presence of mood disorders was also observed in these subjects (14.4 vs. $23.2 \%$ ).

We found several significant correlations between the scales applied, the most significant being those between BDI and PSQI scores (Table 2).

\section{Mood disorders}

Women with mood disorders were older and exhibited longer sleep latency, and shorter total sleep time; accordingly, they showed worse PSQI, ESS, and IRLS scores. Menopausal status was more frequent in this subgroup, as well as an increased prevalence of RLS, OSAS+, and more frequent shift work (Table $3 \mathrm{a} / \mathrm{b})$.

\section{Other disorders and life habits}

Hypertensive women were older $(\mathrm{p}=0.03)$ and had increased BMI $(\mathrm{p}<0.001)$, BDI score $(\mathrm{p}=0.03)$, and mood disorder prevalence $(\mathrm{p}=0.03 ; \mathrm{OR}=2.27)$. A trend towards more frequent RLS (19.6 vs $32.4 \%$ ), shift work ( 25.8 vs. $30.3 \%$ ), and estroprogestinic use (11.2 vs. $17.1 \%$ ) also emerged.

Headache comorbidity was associated with decreased total sleep time $(\mathrm{p}=0.03)$, and worse PSQI ( $\mathrm{p}=0.02)$ and BDI ( $\mathrm{p}=0.004)$ scores. Headache women, particularly those in menopause, showed an increased prevalence of RLS. Headache women showed increased RLS prevalence, particularly in menopausal headache women $(\mathrm{p}=0.04 ; \mathrm{OR}=3.24)$.

Women reporting nicturia were older $(\mathrm{p}=0.007)$ and reported worse PSQI $(\mathrm{p}=0.008), \mathrm{ESS}(\mathrm{p}<0.001)$, BDI $(\mathrm{p}=0.002)$, and IRLS $(\mathrm{p}=0.02)$ scores. Furthermore, in this subgroup, an increased prevalence of mood disorders $(\mathrm{p}=0.004 ; \mathrm{OR}=3.61)$ and hypertension $(\mathrm{p}=<0.001 ; \mathrm{OR}=12.45)$ emerged, as well as a trend towards more frequent menopausal status (30.4 vs. $47.6 \%)$, OSAS+ (23.3 vs. $33.3 \%)$ and RLS (20.5 vs. $28.6 \%$ ) comorbidity.

Shift work women presented increased BMI $(\mathrm{p}=0.01)$ higher BDI $(\mathrm{p}=0.04)$ and IRLS $(\mathrm{p}=0.01)$ scores, as well as increased prevalence of mood disorders $(\mathrm{p}=0.036$ : $\mathrm{OR}=1.93)$ and a trend towards an increased prevalence of headaches (44.9 vs. 52.9\%). Binary logistic regression, considering insomnia, RLS, OSAS+, mood disorders and headaches as dependent variables and life habits (coffee, tea, smoking, alcohol, coke) as categorical independent variables, did not elicit significant associations. Univariate regression, considering the same independent variables, and introducing sleep and mood scales as dependent variables, did not result in sig- 
Table II. - Correlations between sleep and mood scales

\begin{tabular}{|l|c|c|c|}
\hline & PSQI & ESS & BDI \\
\hline PSQI & & 0.198 & 0.499 \\
\hline ESS & 0.198 & & 0.265 \\
\hline BDI & 0.499 & 0.265 & \\
\hline
\end{tabular}

PSQI=Pittsburgh Sleep Quality Index; ESS=Epworth Sleepiness Scale; BDI=Beck Depression Inventory. Correlations with p<0.01, according to Spearman's Q, are reported.

nificant correlations for PSQI and BDI, whereas significant negative correlations were found between smoking $(\mathrm{B}=-1.09, \mathrm{p}=0.015)$ and coffee $(\mathrm{B}=-1.17$, $\mathrm{p}=0.05$ ) habits and ESS score.

We ran a binary logistic regression, considering hypertension as dependent variable, and sleep and mood scale scores as independent variables, finding a significant correlation for $\mathrm{BDI}(\mathrm{OR}=1.1 ; \mathrm{p}=0.027$, $\mathrm{B}=0.062$ ).

A regression analysis conducted introducing the sleep comorbidities examined (insomnia, OSAS+, RLS) disclosed significant associations between OSAS+ (OR 2.0; $\mathrm{p}=0.05 ; \mathrm{B}=0.69)$, and RLS ( $\mathrm{OR}=2.2 ; \mathrm{p}=0.041 ; \mathrm{B}=0.790)$.

Mood disorders, considered as an independent variable, were associated with RLS (OR=1.8; $\mathrm{p}=0.05$; $\mathrm{B}=0.615$ ) when considering sleep disorders as covariates; whereas, when menopausal status, other disorders and life and behavioral habits were considered as covariates, mood disorders resulted correlated to menopause $(\mathrm{OR}=2.2 ; \mathrm{p}=0.042 ; \mathrm{B}=0.78)$, and headaches $(\mathrm{OR}=2.0 ; \mathrm{p}=0.05 ; \mathrm{B}=0.67)$.

Headaches, considered as a dependent variable, were correlated with BDI score $(\mathrm{OR}=1.1 ; \mathrm{p}=0.037$; $\mathrm{B}=0.08$ ), and showed an association with thyroid disease $(\mathrm{OR}=2.9 ; \mathrm{p}=0.031 ; \mathrm{B}=1.052)$ when sleep and medical disorders were employed as covariates.

\section{Discussion}

Sleep problems are common in both genders throughout the entire lifetime, but a series of epidemiological studies reported an increased risk, as high as twofold, for women to develop sleep problems compared to men (Li et al., 2011).

Although sleep problems represent a common issue for young individuals, their incidence increases in midlife (Kravitz et al., 2003), particularly after menopause. Many factors may underlie this relation- ship, which is in part due to climacteric symptoms that are commonly associated with poor subjective sleep (Polo-Kantola et al., 1999), comorbidity with new onset or worsening primary sleep disorders, pain, medical and psychiatric diseases, drugs, and age-related factors (Freedman et al., 2007). Psychosocial, behavioral and stress-related factors may further exacerbate sleep disruption.

In a large French study of women aged between 50 and 64 years, $25 \%$ reported sleep problems, $15 \%$ of which were severe (Leger et al., 2000).

\section{Insomnia}

Insomnia is defined as difficulty in falling asleep or in maintaining sleep or as the feeling of nonrestorative or insufficient sleep, despite adequate opportunity (AASM, 2014).

Our population showed a significant prevalence of insomnia and disrupted sleep, particularly in perimenopausal women, although we could not confirm previous reports of progressive sleep disruption that paralleled the transition from pre to peri and post menopause (Kravitz et al., 2003; Li et al., 2003). This may be related to methodological differences and the smaller population.

Insomnia is often secondary to physical (pain, respiratory or movements disorders, cardiovascular, neurological, rheumatic disorders) or mental conditions, such as mood disorders, since epidemiological studies suggest associations as high as $66-77 \%$ (Soares, 2005; Culpepper, 2006).

Insomniac women showed increased prevalence of mood disorder, headache and more frequent shift work; poor sleep quality as assessed by PSQI was correlated with higher scores in ESS and BDI.

\section{Daytime Sleepiness}

Decreased sleep quality may be associated with EDS or impaired daytime performance. We found higher ESS score in perimenopausal and menopausal ver- 


\begin{tabular}{|l|c|c|c|}
\hline Table Illa. - Mood disorders (BDI $\geq 15)$ & $\begin{array}{c}\text { No mood disorder } \\
(\# 280)\end{array}$ & $\begin{array}{c}\text { Mood disorder } \\
(\# 54)\end{array}$ & $\begin{array}{c}\text { P } \\
\text { Mann-Whitney }\end{array}$ \\
\hline Age, years & $49.4 \pm 3.2$ & $50.2 \pm 3.2$ & 0.034 \\
\hline BMI & $24.8 \pm 4.5$ & $25.1 \pm 6.7$ & N.S. \\
\hline Sleep latency, min & $13.2 \pm 19.4$ & $18.2 \pm 17.6$ & 0.000 \\
\hline Total sleep time, hours & $6.7 \pm 1.1$ & $6.2 \pm 1.2$ & 0.004 \\
\hline PSQI & $5.7 \pm 2.8$ & $9.3 \pm 5.0$ & 0.000 \\
\hline ESS & $5.0 \pm 3.3$ & $6.4 \pm 3.7$ & 0.005 \\
\hline iRLS & $14.2 \pm 5.8$ & $17.5 \pm 6.1$ & 0.024 \\
\hline $\begin{array}{l}\text { BMI=Body Mass Index; PSQI=Pittsburgh Sleep Quality Index; ESS=Epworth Sleepiness Scale; IRLS= The International Restless } \\
\text { Legs Severity Scale. Data are presented as mean } \pm \text { standard deviation. }\end{array}$
\end{tabular}

sus non-menopausal women, and the same relationship was true for pathological sleepiness (defined as ESS > 10). However, another questionnairebased study that evaluated insomnia and sleepiness reported an increased prevalence for insomnia, but no differences in sleepiness scores (Kalleinen et al., 2008). The impact of comorbidities and life habits is emphasized by the greater prevalence of EDS in RLS, and in women suffering from mood disorders, nicturia, and hypertension. However, the lack of a significant association with SDB suggests a peculiar pattern of presentation of this condition in the female population.

\section{Obstructive sleep apnea}

Prevalence of OSAS was estimated to be as high as 9\% in a general female-based population sample. This prevalence may increase in menopausal transition, increasing from $6.5 \%$ to $8.7 \%$, and $16 \%$ in women in their 30s, 40s and 50s respectively (Young, 1993). Previous studies suggest a trend towards increased high risk of OSAS in menopausal women. In our cohort, OSAS+ women showed higher age and BMI. Although sleep apnea risk is related to both age and increasing BMI, a significant role for menopause transition as a risk factor per se in the development of OSAS emerged when controlling for age and BMI (Young et al., 2004). Our data do not support a significant association between OSAS and EDS, suggesting a peculiar clinical presentation for OSAS in female subjects. From a pathophysiological point of view, respiratory events in female subjects may be less severe, with more common partial upper-airway obstruction accounting for the differential impact on EDS (Anttalainen et al., 2007).

\section{RLS}

Similarly to what has been observed in relation to migraine, RLS has been associated with high estrogen levels (Manconi et al., 2012). Accordingly, it is well known that RLS is more common in women than in men (Berger et al., 2004). Despite these facts, increasing prevalence with age has been reported (Nichols et al., 2003). Our data did not confirm increased RLS prevalence from pre to postmenopausal condition, perhaps due to the size of the sample investigated. Albeit not statistically significant, we nevertheless observed increased symptom severity related to the menopausal transition. Although methodological differences have to be taken into account, such findings had already been reported in a previous study (Ghorayeb et al., 2008).

\section{Mood disorders}

More severe symptoms of depression and anxiety have been associated with worse subjective sleep quality perception in middle-aged women (Owens et al., 1998). Since women are at increased risk for major depressive episodes during the perimenopausal period (Cohen et al., 2006), midlife sleep disturbances may constitute an early biomarker of mood disorder. Although it is difficult to determine whether poor sleep precedes the onset of mood disorders, the association of the latter with sleep disruption seems likely and has been reported in several studies, although the nature of this association is yet to be fully understood. The "domino hypothesis" suggests that vasomotor symptoms, associated with decreasing estrogen levels, translate into a sleep disruption that in turn may negatively impact mood (Campbell et at., 1977; Burleson et al., 2010). 


\begin{tabular}{|c|c|c|c|c|}
\hline \multicolumn{5}{|c|}{ Table Illb. - Mood disorders (BDI $\geq 15$ ) } \\
\hline & $\begin{array}{c}\text { No mood disorder } \\
(\# 280)\end{array}$ & $\begin{array}{c}\text { Mood disorder } \\
(\# 54)\end{array}$ & $\begin{array}{c}\mathrm{P} \\
\text { chi-square }\end{array}$ & OR \\
\hline Shift work & $24.4 \%$ & 36.7 & NS & \\
\hline RLS & $19.0 \%$ & $29.5 \%$ & 0.09 & 1.78 \\
\hline Menopause & $29.4 \%$ & $44.4 \%$ & 0.025 & 1.93 \\
\hline OSAS+ & $23.7 \%$ & $32.8 \%$ & NS & \\
\hline
\end{tabular}

Epidemiological studies suggest a strong relationship between insomnia and depression, thus implying that insomnia is not only a typical core symptom of depression, but may also be considered an independent risk factor for the development of mood disorders in the long run (Riemann et al., 2001).

\section{Other disorders and life habits}

Hypertensive women were older and had increased BMI, BDI score, and mood disorder prevalence. A trend towards increased IRLS scores, and more frequent RLS, shift work, and estroprogestinic use was observed (Table 9a/b).

Sleep quality has been identified as a factor associated with hypertension (Calhoun et al., 2010).

Untreated sleep disorders such as insomnia, OSAS, and RLS with periodic leg movements during sleep (PLMS) may contribute, at least in part, as secondary causes of uncontrolled hypertension and cardiovascular disease (CVD) (Walters \& Rye, 2009). Epidemiological studies show an association between RLS and PLMS, hypertension and CVD, resulting in an increased prevalence and incidence of hypertension, CVD, and cerebrovascular disease in patients diagnosed with RLS/PLMS (FeriniStrambi et al., 2013). Observational studies provide additional physiologic evidence demonstrating that RLS/PLMS increases several CVD risk factors, such as blood pressure (BP) and heart rate, with reduced nocturnal BP dipping (Walters et al., 2010). Pharmacologic treatment of RLS/PLMS may reduce $\mathrm{BP}$ and the incidence of vascular complications in patients with RLS/PLMS. Insomnia and OSAS also contribute to an increased risk for hypertension and CVD, albeit likely through different mechanisms. Low levels of estrogen seem to have a marked influence on headaches as the prevalence of migraine and other headache types markedly decreases between the ages of 50 and 60 (Brandes, 2006). In agreement with the literature, we found a reduction of headache prevalence in the postmenopausal status.

Sleep disturbances are frequent during menopausal transition. The etiology is unclear, but probably multifactorial, including vasomotor symptoms, fluctuating reproductive hormone levels, primary sleep disorders (primary insomnia, RLS, OSAS), mood disorders, medical conditions, lifestyle factors, etc. It is imperative to investigate sleep problems associated with menopause, by collecting basic sleep history and evaluating behavioral and circadian factors that may contribute to sleep disturbances. Ultimately, sleep recordings could be performed to help elucidate complex or controversial cases. Pharmacological and behavioral treatment strategies should be aimed at improving quality of sleep, and thus of life, in menopausal women.

Further research should be encouraged for a comprehensive evaluation of this delicate transitional phase in which sleep, through its major changes, plays a pivotal role.

\section{References}

American Academy of Sleep Medicine AASM. The international classification of sleep disorders $3 \mathrm{rd}$. 2014, Darien IL: AASM.

Anttalainen U., Saaresranta T., Kalleinen N., Aittokallio J., Vahlberg T., Polo O. Gender differences in age and BMI distributions in partial upper airway obstruction during sleep. Respir. Physiol. Neurobiol., 159: 219-226, 2007.

Beck A.T., Steer R.A., Carbin M.G. Psychometric properties of the Beck Depression Inventory: twenty-five years of evaluation. Clin. Psychol. Rev., 8: 77-100, 1988. 
Berger K., Luedemann J., Trenkwalder C., John U., Kessler C. Sex and the risk of restless legs syndrome in the general population. Arch. Intern. Med., 164: 196-202, 2004.

Brandes J.L. The influence of estrogen on migraine: a systematic review. JAMA, 295: 1824-1830, 2006.

Bruyneel M. Sleep disturbances in menopausal women: Aetiology and practical aspects. Maturitas, 81: 406-409, 2015.

Burleson M.H., Todd M., Trevathan W.R. Daily vasomotor symptoms, sleep problems, and mood: using daily data to evaluate the domino hypothesis in middle-aged women. Menopause, 17: 87-95, 2010.

Buysse D.J., Reynolds III C.F., Monk T.H., Berman S.B., Kupfer D.J. The Pittsburgh Sleep Quality Index: A new instrument for psychiatric practice and research. Psychiatry Res., 28: 193-221, 1989.

Calhoun D.A. and Harding S.M. Sleep and hypertension. Chest, 138: 434-443, 2010.

Cohen L.S., Soares C.N., Vitonis A.F., Otto M.W., Harlow B.L. Risk for new onset of depression during the menopausal transition: the Harvard study of moods and cycles. Arch. Gen. Psychiatry, 63: 385-390, 2006.

Culpepper L. Secondary insomnia in the primary care setting: review of diagnosis, treatment, and management. Curr. Med. Res. Opin., 22: 1257-68, 2006.

Ferini-Strambi L., Walters A.S., Sica D. The relationship among restless legs syndrome (Willis-Ekbom Disease), hypertension, cardiovascular disease, and cerebrovascular disease. J. Neurol, 261: 10511068, 2014.

Freedman R.R. and Roehrs T.A. Sleep disturbance in menopause. Menopause, 14: 826-829, 2007.

Ghorayeb I., Bioulac B., Scribans C., Tison F. Perceived severity of restless legs syndrome across the female life cycle. Sleep Med., 9: 799-802, 2008.

Guidozzi F. Sleep and sleep disorders in menopausal women. Climacteric, 16: 214-219, 2013.

Hachul H., Frange C., Bezerra A.G. et al. The effect of menopause on objective sleep parameters: data from an epidemiologic study in São Paulo, Brazil. Maturitas, 80: 170-178, 2015.

Joffe H., Massler A., Sharkey K.M.. Evaluation and Management of Sleep Disturbance During the Menopause Transition. Semin. Reprod. Med., 28: 404-421, 2010.

Johns M.W. A new method for measuring daytime sleepiness: the Epworth sleepiness scale. Sleep, 14: 540-545, 1991.
Kalleinen N., Polo-Kantola P., Himanen S.L., Alhola P., Joutsen A., Urrila A.S., Polo O. Sleep and the menopause - do postmenopausal women experience worse sleep than premenopausal women? Menopause Int., 14: 97-104, 2008.

Kravitz H.M., Ganz P.A., Bromberger J., Powell L.H., Sutton-Tyrrell K., Meyer P.M. Sleep difficulty in women at midlife: a community survey of sleep and the menopausal transition. Menopause, 10: 19-28, 2003.

Leger D., Guilleminault C., Dreyfus J.P., Delahaye C., Paillard M. Prevalence of insomnia in a survey of 12,778 adults in France. J. Sleep Res., 9: 35-42, 2000.

Li R.H., Wing Y.K., Ho S.C., Fong S.Y. Gender differences in insomnia--a study in the Hong Kong Chinese population. J. Psychosom. Res., 53: 601609, 2002.

Manconi M., Ulfberg J., Berger K., Ghorayeb I., Wesström J., Fulda S., Allen R.P., Pollmächer T. When gender matters: restless legs syndrome. Report of the "RLS and woman" workshop endorsed by the European RLS Study Group. Sleep Med. Rev., 4: 297-307, 2012.

Marin J.M., Carrizo S.J., Vicente E., Agusti A.G. Long-term cardiovascular outcomes in men with obstructive sleep apnoea-hypopnoea with or without treatment with continuous positive airway pressure: an observational study. Lancet, 365: 1046-1053, 2005.

McKinkay S.M., Brambilla D.J., Posner J.G. The normal menopause transition. Maturitas, 61: 1-2, 2008.

Netzer N.C., Stoohs R.A., Netzer C.M., Clark K., Strohl K.P. Using the Berlin Questionnaire to identify patients at risk for the sleep apnea syndrome. Ann. Intern. Med., 131: 485-491, 1999.

Nichols D.A., Allen R.P., Grauke J.H., Brown J.B., Rice M.L., Hyde P.R., Dement W.C., Kushida C.A. Restless legs syndrome symptoms in primary care: a prevalence study. Arch. Intern. Med., 163: 2323-2329, 2003.

Owens J.F. and Matthews K.A. Sleep disturbance in healthy middle-aged women. Maturitas, 30: 41-50, 1998.

Polesel D.N., Hirotsu C., Nozoe K.T., Boin A.C., Bittencourt L., Tufik S., Andersen M.L., Hachul H. Waist circumference and post-menopause stages as the main associated factors for sleep apnea in women: a cross-sectional population-based study. Menopause, 22: 835-844, 2015.

Polo-Kantola P., Erkkola R., Irjala K., Helenius H., Pullinen S., Polo O. Climacteric symptoms and sleep quality. Obstet. Gynecol., 94: 219-224, 1999. 
Riemann D., Berger M., Voderholzer U. Sleep and depression-results from psychobiological studies: an overview. Biol. Psychol., 57: 67-103, 2001.

Soares C.N. Insomnia in women: an overlooked epidemic? Arch. Womens Ment. Health, 4: 205-213. 2005.

Taavoni S., Ekbatani N.N., Haghani H. Postmenopausal women's quality of sleep and its related factors. Midlife Health, 6: 21-25, 2015.

Walters A.S., LeBrocq C., Dhar A. et al. Validation of the International Restless Legs Syndrome Study Group rating scale for restless legs syndrome. Sleep Med., 4: 121-132, 2003.

Walters A.S., Moussouttas M., Siddiqui F., et al. Prevalence of stroke in restless legs syndrome: initial results point to the need for more sophisticated studies. Open. Neurol. J., 4: 73-77, 2010.
Walters A.S., Rye D.B. Review of the relationship of restless legs syndrome and periodic limb movements in sleep to hypertension, heart disease, and stroke. Sleep, 32: 589-597, 2009.

Woodward S. and Freedman R.R. The thermoregulatory effects of menopausal hot flashes on sleep. Sleep, 6: 497-501, 1994.

Xu Q., Lang C.P., Rooney N. A systematic review of the longitudinal relationships between subjective sleep disturbance and menopausal stage. Maturitas, 79: 401-412, 2014.

Young T. Analytic epidemiology studies of sleep disordered breathing-what explains the gender difference in sleep disordered breathing? Sleep, 8: S1-2, 1993.

Young T., Skatrud J., Peppard P.E. Risk factors for obstructive sleep apnea in adults. JAMA, 16: 20132016, 2004. 